\title{
Does Type D Personality Impact on the Prognosis of Patients Who Underwent Catheter Ablation for Atrial Fibrillation? A 1-Year Follow-Up Study
}

\author{
Sang Won Jeon ${ }^{1 *}$, Hong Euy Lim ${ }^{2 *}$, Seoyoung Yoon ${ }^{3}$, Kyoung Se $\mathrm{Na}^{4}$, \\ Young-Hoon $\mathrm{Ko}^{3 凶}$, Sook-Haeng Joe ${ }^{5}$, and Young-Hoon $\mathrm{Kim}^{2}$ \\ 1'Department of Psychiatry, Kangbuk Samsung Hospital, Sungkyunkwan University School of Medicine, Seoul, Republic of Korea \\ 2Division of Cardiology, Department of Internal Medicine, Korea University Medical Center, Seoul, Republic of Korea \\ ${ }^{3}$ Department of Psychiatry, Korea University Ansan Hospital, Korea University College of Medicine, Ansan, Republic of Korea \\ ${ }^{4}$ Department of Psychiatry, Gachon University Gil Medical Center, Incheon, Republic of Korea \\ ${ }^{5}$ Department of Psychiatry, Korea University Guro Hospital, Korea University College of Medicine, Seoul, Republic of Korea
}

Objective Although Type D personality has been associated with the prognosis of various cardiac diseases, few studies have investigated the influence of Type D personality on the cardiac and psychiatric prognoses of patients with atrial fibrillation (AF).

Methods Depression, anxiety, and quality of life were measured at baseline and 6 months. The recurrence of AF was measured during 1-year following radiofrequency catheter ablation (RFCA) for AF. The Kaplan-Meier method with log-rank tests were used to compare the cumulative recurrence of AF. ACox proportional hazard model was conducted to identify factors that contribute to the recurrence of AF.

Results A total of 236 patients admitted for RFCA were recruited. Patients with a Type D personality had higher levels of depression and anxiety and a poorer quality of life compared to controls. Although depression, anxiety, and quality of life had improved 6 months after RFCA, significant differences in psychiatric symptoms remained between patients with and without Type D personality. In the Cox models, the type of AF was the only factor that influenced the recurrence of $\mathrm{AF}$.

Conclusion Our results suggest that Type D personality predominately influences psychological distress in patients with AF, but not the recurrence of AF.

Psychiatry Investig 2017;14(3):281-288

Key Words Anxiety, Atrial fibrillation, Depression, Type D personality, Quality of life.

\section{INTRODUCTION}

Type $\mathrm{D}$ personality is characterized by negative affectivity (NA, the tendency to experience negative emotions) and social inhibition (SI, the tendency to inhibit the expression of emotions). ${ }^{1}$ The differences between type D personality and depression are as follows: 1) SI construct within type D personality, which indicate to how patients cope with NA, is significantly more than a measure of depression; ${ }^{2} 2$ ) depression

\footnotetext{
Received: December 14, 2015 Revised: May 20, 2016

Accepted: June 3, 2016 Available online: February 27, 2017

$\triangle$ Correspondence: Young-Hoon Ko, MD, PhD

Department of Psychiatry, Korea University Ansan Hospital, Korea University College of Medicine, 123 Jeokgeum-ro, Danwon-gu, Ansan 15355, Republic of Korea Tel: +82-31-412-5140, Fax: +82-31-412-5144, E-mail: korean@chol.com

*These authors contributed equally to this work.

(a) This is an Open Access article distributed under the terms of the Creative Commons Attribution Non-Commercial License (http://creativecommons.org/licenses/bync/4.0) which permits unrestricted non-commercial use, distribution, and reproduction in any medium, provided the original work is properly cited.
}

reflects a psychopathology, whereas type D reflects a normal personality construct; 3 ) depression can changes according to current psychological states, whereas type $\mathrm{D}$ remains stable during a person's life time. ${ }^{3}$ Therefore, this personality approach may improve our understanding of individual differences in cardiovascular events, and may be used as screening instrument in order to identify high risk patients.

Previous studies have reported that Type D personality was associated with poor quality of life, depression, and increased mortality in patients with cardiovascular diseases. ${ }^{4-6}$ Furthermore, type D independently predicted adverse cardiac events, after adjustment for severity of depression. ${ }^{7-10}$ However, despite the important role of Type $\mathrm{D}$ personality in cardiovascular diseases, few studies have investigated the potential role of Type D personality in the cardiac and psychiatric prognoses of atrial fibrillation (AF). One study reported that Type D patients were at risk of ventricular arrhythmia and that depressive symptoms were not associated witharrhythmia, ${ }^{11}$ whereas 
another study reported that depression but not Type D was related to atrial fibrillation. ${ }^{12}$ It was also reported that Type $\mathrm{D}$ predicts the occurrence of life threatening arrhythmias following implantable cardioverter defibrillator (ICD) treatment. ${ }^{6}$

Atrial fibrillation (AF) is one of the most frequent types of symptomatic arrhythmia, affecting 2 to 3 million individuals in the United States. ${ }^{13} \mathrm{AF}$ is associated with substantial mortality and cardiac complications. ${ }^{14}$ Approximately $25 \%$ of patients with $\mathrm{AF}$ have a chronic course ${ }^{15}$ and emotional distress may impact on $\mathrm{AF}$, although the exact mechanisms by which emotional distress induces AF have not been comprehensively investigated. Emotional distress has been associated with autonomic nervous system alterations, which specifically respond to the nature of emotions. ${ }^{16}$ Negative emotions frequently found in Type D personality, such as anger, anxiety, and depression, may be associated with AF. Anger may contribute to arrhythmia by disturbing a repolarization stability measured by $\mathrm{T}$ wave alternans. ${ }^{17}$ Depression and anxiety have also been related to increased sympathetic nervous system activity, which in turn contributes to paroxysmal $\mathrm{AF}^{18}$

The potentially deleterious effects of Type $\mathrm{D}$ on AF werealso supported by the association with inflammatory reaction. Several reports suggested that inflammatory markers, such as interleukin-6 and high-sensitivity C-reactive protein (hsCRP), were significantly related to the recurrence or incidence of $\mathrm{AF}^{19}$ The inflammatory markers such as tumor necrosis factor-alpha (TNF) and TNF receptor 2 as well as hsCRP were increased in patients with type $\mathrm{D}$ personality. ${ }^{20,21}$ Moreover, in AF patients with Type D, hsCRP levels were higher than those without Type D personality. ${ }^{22}$ Although the mechanism linking type $\mathrm{D}$ to $\mathrm{AF}$ through inflammation is not determined yet, it is thought that there are various pathways including autonomic imbalance ${ }^{16}$ or heart rate variability. ${ }^{23}$ Consequently, increased adrenergic tone and a pro-inflammatory state are possible mechanisms responsible for the association between personality $\mathrm{D}$ and AF.

Despite these associations, to the best of our knowledge, few studies ${ }^{6,11,12}$ have examined the effects of Type D personality on the psychiatric and cardiac prognosis in patients with $\mathrm{AF}$. In this prospective study, we examined the adverse effects of Type D personality on the stability of the sinus rhythm after radiofrequency catheter ablation (RFCA) for AF and psychological impact of Type D construct in patients with AF. In addition, Type $\mathrm{D}$ was also investigated as a continuous variable including the multiplicative interaction term of NA and SI because recent studies suggested that dichotomization of NA and SI has the potential formis leading results.

\section{METHODS}

\section{Subjects}

We consecutively enrolled 239 patients who underwent RFCA for paroxysmal AF (PAF, $n=172$ ) and persistent AF (PeAF, $\mathrm{n}=64$ ). PAF or PeAF were defined according to the most recent guidelines of the Heart Rhythm Society and the European Cardiac Arrhythmia Society. ${ }^{18}$ Exclusion criteria were any acute or chronic infections or inflammatory diseases, the presence of visible thrombi in left atrium (LA) by transesophageal echocardiography (TEE), previous AF ablation or cardiac surgery, aortic aneurysm or dissection, hepatic or renal disease, an acute cerebrovascular event within the preceding 3 months, any major trauma or surgery within the preceding 3 months, hyperthyroidism, uncontrolled hypertension, malignancy, and connective tissue diseases. All anti-arrhythmic drugs were discontinued at least five half-lives prior to the examination. All patients were on continuous anticoagulation therapy with a target international normalized ratio of 2 to 3. Patients were also excluded if they suffered from other life-threatening diseases or cognitive impairments, had a history of psychiatric disorders, or were unable to understand and read Korean.

Patients participated after being extensively informed about the study and giving written informed consent. The study protocol was reviewed and accepted by the institutional review board of the Korea University Ansan hospital and the study was performed in accordance with the Declaration of Helsinki.

\section{Measures}

\section{Korean version of the 14-item Type D Scale (DS14KR)}

Type D personality was assessed with the DS14, which measures NA and SI. ${ }^{1}$ Each item is rated according to a 5-point Likert scale from 0 (false) to 4 (true). Patients who scored high on both NA and SI, as determined by a cut-off of 10 on both scales, were classified as Type D. The Cronbach's alpha was 0.88 for the NA and 0.86 for the SI; the test-retest reliability was 0.86 and 0.80 for the NA and SI, respectively, in the DS14KR. ${ }^{24}$

\section{Center for Epidemiologic Studies Depression Scale (CESD)}

The CESD is a short self-report scale designed to measure depressive symptoms. ${ }^{25}$ To examine the extent to which DS14 scores were affected by mood status, the subjects completed the Korean version of the CESD. The CESD contains 20 items, and each item is scored on a 4-point scale ranging from 0 to 3 . A score of 16 and 25 as the optimal cutoff point was suggested as probable depression and definite depression, respectively. ${ }^{25}$ The internal consistency of the Korean version was $0.89 .{ }^{26}$ 
State subscale of the Spielberger State and Trait Anxiety Inventory (STAI-S)

We investigated anxiety using the STAI-S ${ }^{27}$ to examine the extent to which DS14 scores were affected by the anxiety status of the subjects. The items of this subscale are answered on a 4-point Likert scale from 1 (not at all) to 4 (very much so). The Cronbach's alpha of the State Anxiety scale was 0.92 for the Korean version. ${ }^{28}$

\section{The short version of World Health Organization Quality of Life assessment instrument (WHOQOL-BREF)}

The WHOQOL-BREF is a self-report measure with 2 general questions (on QOL and satisfaction with health) and 24 specific questions assessing four QOL domains: Physical (7 items), Psychological (6 items), Social Relationships (3 items), and Environmental ( 8 items). The internal consistency of the Korean version was $0.898{ }^{29}$

\section{Procedures}

\section{Transthoracic echocardiography}

All examinations were performed using a commercially available Vivid $7^{\mathrm{TM}}$ (GE Medical System, Vingmed, Horten, Norway) ultrasound system. All recorded echocardiograms were collected and analyzed using an off-line computer analysis station (Echopac ${ }^{\mathrm{TM}}$ 6.3.4; GE Medical Systems). All measurements were taken from three consecutive cardiac cycles and averaged.

\section{Ablation procedure}

A stepwise ablation procedure was employed in all AF patients, regardless of AF type. Initially, all patients underwent wide circumferential pulmonary vein isolation (CPVI). For patients who remained in sinus rhythm (SR) after CPVI, an inducibility test with $10 \mathrm{~mA}$ pacing was performed in the high right atrium or coronary sinus using a pacing cycle length of $180 \mathrm{~ms}$ with a 1:1 capture. If induced AF was sustained for more than 10 minutes without isoproterenol infusion or patients who remained in AF after CPVI, an additional ablation of complex fractionated atrial electrogram (CFAEs) sites on both atria was completed until the termination of AF was observed. In cases where AF converted to organized atrial flutter (AFL), and a local activation time map was created during stable AFL. Several rounds of radiofrequency energy were then delivered to the critical isthmus or foci until AFL termination was observed. In patients with PeAF and/or induced typical AFL, a cavotricuspid isthmus line was created and the bidirectional block was confirmed by a differential pacing maneuver. If subjects remained in AF up to 5 hours after beginning RFCA, we performed DC cardioversion to restore SR.

\section{Psychiatric assessment and follow-up}

An in person research interview was conducted to screen and identify potential patients groups. The AF patients completed the DS14, the STAI-S, the CESD, and the WHOQOLBREF at the time of hospital admission for RFCA for AF. All enrolled subjects were prospectively followed to monitor undetected AF for at least 12 months after discharge via monthly outpatient clinic visits. Subjects also underwent 3-channel 48-hour Holter monitoring at 1, 3, 6, and 12 months post discharge. An ECG was performed during each visit and anytime the subjects reported palpitations. Subjects were also questioned via telephone by a nurse practitioner at 2 week intervals and were instructed to call whenever they experienced symptoms. To examine changes in negative emotions and quality of life over 6 months, the patients completed the questionnaires at 6 months. If the patients did not visit the clinic at 6 months for the follow-up evaluation, only baseline data were analyzed. However, as telephone evaluations and other follow-up visits occurred, these patients were included in the survival analyses. For the event-free survival analysis, the study ended 12 months after the last patient was enrolled.

\section{Statistical analyses}

The descriptive statistics for each variable were calculated. Baseline characteristics were compared between the Type D and non-Type D groups using independent t-tests. The frequencies of categorical data were analyzed using chi-square or Fisher exact tests, when appropriate. A multivariate analysis of covariance (MANCOVA) was used to compare the two groups for the scores on each measure at baseline; sex, age, partner, education, body mass index, CHADS2 score (risk of stroke in atrial fibrillation using the Cardiac failure, Hypertension, Age, Diabetes Stroke system), history of coronary arterial disease, left atrial dimension, left ventricular ejection fraction, type of AF, and comorbid medical disorders including diabetes and hypertension were used as covariates. The changes in scores on each measure over 6 months were analyzed using repeated measured MANCOVA with the same covariates. Missing items were replaced with the mean value of the completed items in each scale. The number of missing values on each item was less than $1.5 \%$.

The recurrence rates were estimated using the KaplanMeier method. The Log-rank test was used to compare recurrence probabilities according to the selected covariates. Next, a multivariate analysis with Cox regression was performed to estimate whether type D or its constituents, NA and SIwere an independent predictor of AF recurrence. A first series of models was created adjusting for Type D and other variables which were known as risk factors of AF; sex, age, partner, education, body mass index, CHADS2 score, history of coro- 
nary arterial disease, left atrial dimension, left ventricular ejection fraction, type of AF, comorbid medical disorders including diabetes and hypertension, and scores on the CESD, STAI-S, and WHOQOL-BREF. In a second series of models, the continuous NA and SI raw data were substituted for the categorized type $\mathrm{D}$ variable in the independent variables of the first series of models. These were analyzed with and without the interaction term between NA and SI. The results

Table 1. Baseline characteristics of patients stratified with Type D personality $(\mathrm{N}=236)$

\begin{tabular}{|c|c|c|c|c|}
\hline Variables & Non-Type D $(\mathrm{N}=163)$ & Type D (N=73) & $\chi^{2}$ or $t$ & $\mathrm{p}$ \\
\hline Sex, N (\%) & & & 0.11 & 0.86 \\
\hline Men & $131(80.4)$ & $60(82.2)$ & & \\
\hline Women & $32(19.6)$ & $13(17.8)$ & & \\
\hline Age (year), mean (SD) & $55.9(12.0)$ & $55.6(11.9)$ & 0.15 & 0.88 \\
\hline Education level, N (\%) & & & 5.4 & 0.25 \\
\hline None & $3(1.8)$ & $1(1.4)$ & & \\
\hline Elementary school & $16(9.8)$ & $5(6.8)$ & & \\
\hline Middle school & $14(8.6)$ & $13(17.8)$ & & \\
\hline High school & $41(25.2)$ & $21(28.8)$ & & \\
\hline Over college & $89(54.5)$ & $33(44.2)$ & & \\
\hline With partner, N (\%) & & & 1.77 & 0.19 \\
\hline Yes & $148(90.8)$ & $62(84.9)$ & & \\
\hline No & $15(9.2)$ & $11(15.1)$ & & \\
\hline BMI $\left(\mathrm{kg} / \mathrm{m}^{2}\right)$, mean $(\mathrm{SD})$ & $24.8(2.7)$ & $25.1(2.5)$ & -1.07 & 0.28 \\
\hline CHADS2, mean (SD) & $1.4(1.3)$ & $1.3(1.0)$ & 0.30 & 0.76 \\
\hline $\mathrm{LAD}(\mathrm{mm})$, mean $(\mathrm{SD})$ & $42.1(7.2)$ & $40.2(6.2)$ & 1.86 & 0.06 \\
\hline $\operatorname{LVEF}(\%)$, mean $(\mathrm{SD})$ & $63.5(9.2)$ & $63.7(7.9)$ & -0.16 & 0.88 \\
\hline Type of AF, N (\%) & & & 0.23 & 0.27 \\
\hline PAF & $115(70.6)$ & $57(78.1)$ & & \\
\hline PeAF & $48(29.4)$ & $16(21.9)$ & & \\
\hline History of CAD, N (\%) & & & 0.32 & 0.36 \\
\hline Yes & $18(7.6)$ & $5(2.1)$ & & \\
\hline No & $145(61.4)$ & $68(93.2)$ & & \\
\hline Comorbid disorder, N (\%) & & & 1.29 & 0.73 \\
\hline None & $110(67.5)$ & $54(63.0)$ & & \\
\hline Hypertension & $37(22.7)$ & $14(24.7)$ & & \\
\hline Diabetes mellitus & $5(3.1)$ & $1(6.8)$ & & \\
\hline Both & $11(6.7)$ & $4(5.5)$ & & \\
\hline \multicolumn{5}{|c|}{ Psychiatric measurement, mean (SD) } \\
\hline CESD & $11.0 \pm 8.8$ & $18.1 \pm 10.5$ & -5.39 & $<0.001$ \\
\hline STAI-S & $39.9 \pm 8.9$ & $48.9 \pm 9.6$ & -7.05 & $<0.001$ \\
\hline \multicolumn{5}{|l|}{ WHOQOL-BREF } \\
\hline Total & $79.6 \pm 14.9$ & $70.1 \pm 12.5$ & 4.73 & $<0.001$ \\
\hline General & $6.1 \pm 1.3$ & $5.5 \pm 1.3$ & 3.24 & 0.001 \\
\hline Physical & $21.5 \pm 4.9$ & $18.6 \pm 4.1$ & 4.21 & $<0.001$ \\
\hline Psychological & $11.8 \pm 3.5$ & $10.2 \pm 4.0$ & 5.25 & $<0.001$ \\
\hline Social & $8.4 \pm 2.2$ & $7.4 \pm 2.1$ & 3.29 & 0.001 \\
\hline Environmental & $23.8 \pm 5.4$ & $21.6 \pm 5.1$ & 2.81 & 0.005 \\
\hline
\end{tabular}

BMI: body mass index, CHADS2: risk of stroke in atrial fibrillation using the Cardiac failure, Hypertension, Age, Diabetes Stroke system, LAD: left atrial dimension, LVEF: left ventricular ejection fraction, AF: atrial fibrillation, PAF: paroxysmal atrial fibrillation, PeAF: persistent atrial fibrillation, CAD: coronary arterial disease, CESD: Center for Epidemiologic Studies Depression Scale, STAI-S: State subscale of the Spielberger State and Trait Anxiety Inventory, WHOQOL-BREF: short version of World Health Organization Quality of Life assessment instrument 
from these calculations are reported as adjusted hazard ratios with their associated 95\% confidence intervals (CIs). All tests were 2 -tailed and a probability value $<0.05$ was used to indicate statistical significance. All data were analyzed using PASW Statistics 20 statistical software (PASW IBM Corp, Armonk, NY, USA).

\section{RESULTS}

\section{Subjects}

Of the 239 patients eligible and screened for study participation, three (1.3\%) patients were excluded from baseline statistical analyses because of a lack of demographic data or no scores on the DS14. Thus, a total of 236 patients were included in the study. One hundred and five (43.9\%) patients completed the baseline and the 6-month questionnaires.

Baseline characteristics for the subjects stratified by Type $\mathrm{D}$ personality are presented in Table 1 . Of the 236 patients, $30.1 \%(n=66)$ of patients had a Type D personality. A total of $72.9 \%(n=172)$ of patients suffered from paroxysmal AF, and $24.1 \%(n=64)$ of patients had persistent AF. There was no significant difference in the baseline variables between the Type $\mathrm{D}$ and non-Type $\mathrm{D}$ groups, as presented in Table 1.

\section{Recurrence of atrial fibrillation}

During the 1-year follow-up, 94 patients (57.7\%) in the nonType D group and 45 patients (61.6\%) in the Type D group suffered from a recurrence of AF. There were no significant differences in recurrence rates between the two groups (Figure 1). The mean survival times were 28.3 weeks for both groups. Using the Cox proportional hazards regression model, only the type of AF was found to significantly influence the onset of AF recurrence. Persistent AF was associated with an earlier recurrence [hazard ratio $(\mathrm{HR})=0.66,95 \% \mathrm{CI}=0.45-0.96, \mathrm{p}=$ 0.03). The impact of its two components (NA and SI) were also tested over the follow-up period. There were no significant differences in recurrence rates between elevated and nor- mal scores on the NA and SI subscales $(\geq 10)$, respectively. The corresponding Kaplan-Meier curves were showed in Figure 1. After adjustment for other covariates as predictors of outcomes in the Cox model, the continuous raw data on the NA and SI subscales and their interaction termfailed to predict recurrence of $\mathrm{AF}$.

\section{Depression, anxiety, and quality of life}

At baseline, the Type $\mathrm{D}$ personality group had significantly higher mean scores $(18.1 \pm 10.5)$ on the CESD than the nonType D personality group $(11.0 \pm 8.8 ; \mathrm{t}=-5.39, \mathrm{p}<0.001)$. The mean scores on the STAI-S were significantly higher in the Type D personality group $(48.9 \pm 9.6)$ compared to the nonType $\mathrm{D}$ personality group (39.9 $\pm 8.9 ; \mathrm{t}=-7.05, \mathrm{p}<0.001)$.

There were significant differences in the total scores on the WHOQOL-BREF and its domains between the Type D personality and non-Type D personality groups: total scores for Type $\mathrm{D}$ and non-Type $\mathrm{D}$ personality were $70.1 \pm 12.5$ and $79.6 \pm 14.9$, respectively $(\mathrm{t}=4.73, \mathrm{p}<0.001)$; general domain scores were $5.5 \pm 1.3$ and $6.1 \pm 1.3$, respectively $(\mathrm{t}=3.24, \mathrm{p}=0.001)$; physical domain scores were $18.6 \pm 4.1$ and $21.5 \pm 4.9$, respectively ( $\mathrm{t}=4.21, \mathrm{p}<0.001)$; psychological domain scores were $10.2 \pm 4.0$ and $11.8 \pm 3.5$, respectively $(\mathrm{t}=5.25, \mathrm{p}<0.001)$; social domain scores were $7.4 \pm 2.1$ and $8.4 \pm 2.2$, respectively $(\mathrm{t}=3.29$, $\mathrm{p}=0.001$ ); and environmental domain scores were 21.6 \pm 5.1 and 23.8 \pm 5.4 , respectively $(\mathrm{t}=2.81, \mathrm{p}=0.005)$.

Repeated-measures analyses using MANCOVAs $(n=105)$ indicated that there was a significant interaction effect between time and group $\left(\mathrm{F}_{1,93}=6.05, \mathrm{p}=0.016\right)$, and a significant difference between groups $\left(\mathrm{F}_{1,93}=17.44, \mathrm{p}<0.001\right)$ in the STAI$\mathrm{S}$ scores over the 6 month follow-up period. There was also a difference in the CESD scores between the two groups $\left(\mathrm{F}_{1,93}=\right.$ 13.82, $\mathrm{p}<0.001$ ) (Figure 2). Similar results were shown for the total scores on the WHOQOL-BREF and the domainscores. For the total scores, there was a significant difference between groups $\left(\mathrm{F}_{1,93}=7.61, \mathrm{p}=0.007\right)$ with an interaction effect between time and group $\left(\mathrm{F}_{1,93}=7.35, \mathrm{p}=0.008\right)$. The physical domain
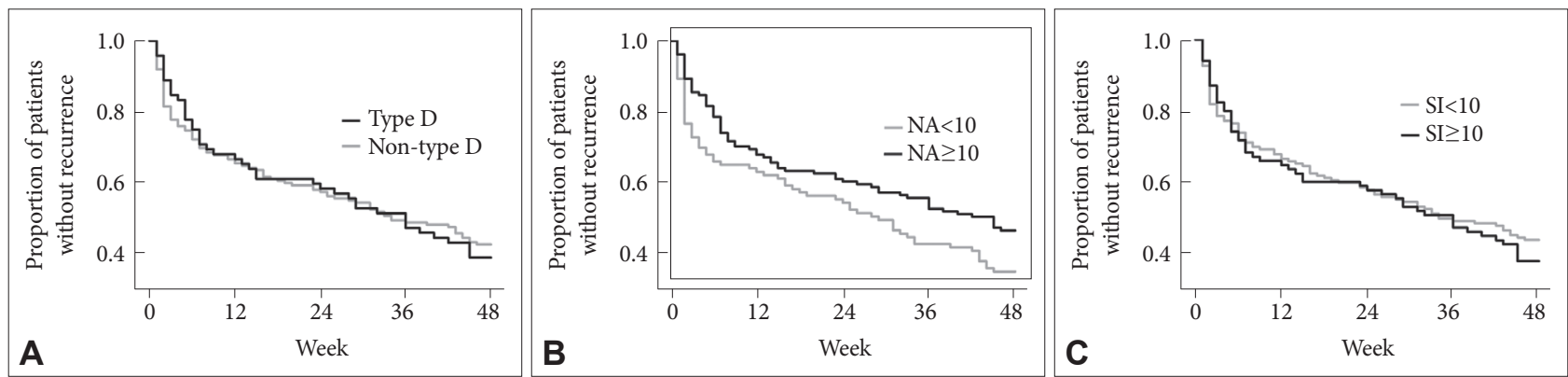

Figure 1. Proportions of patients with atrial fibrillation remaining without recurrence 1 year after ablation in patients with atrial fibrillation by type D personality (A) and each of its two constituent components, negative affectivity (NA) (B) and social inhibition (C), respectively. Eventfree survival rates are presented for patients classified either as Type D versus non-Type D or elevated versus normal scores on the negative affectivity and social inhibition $(\mathrm{SI})$ subscales of 14-item type $\mathrm{D}$ scale $(\geq 10)$, respectively. 


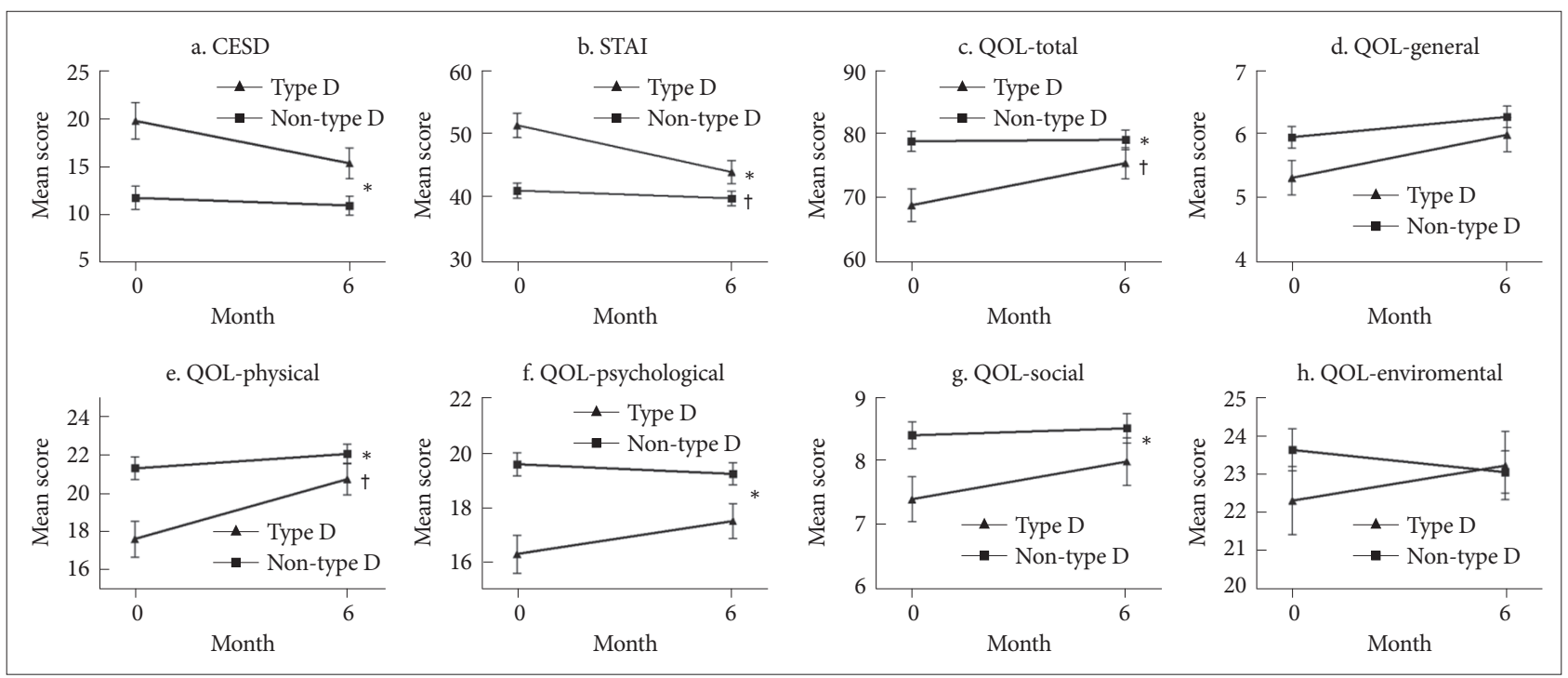

Figure 2. Mean change in the scores on the measures stratified by Type $D$ personality $(\mathrm{N}=105)$. *a significant group difference, ${ }^{+}$a significant time and group interaction, analyzed using repeated measure multivariate analysis of covariance. CESD: Center for Epidemiologic Studies Short Depression Scale, STAI: State subscale of Spielberger State and Trait Anxiety Inventory, QOL: short version of World Health Organization Quality of Life assessment instrument.

was also significantly different between groups $\left(\mathrm{F}_{1,93}=7.71\right.$, $\mathrm{p}=0.007)$ with interaction effects between time and group $\left(\mathrm{F}_{1,93}=6.78, \mathrm{p}=0.011\right)$. In the psychological and social domains, a significant difference between groups (psychological: $\mathrm{F}_{1,93}=$ 15.37, $\mathrm{p}<0.001$; social: $\mathrm{F}_{1,93}=6.65, \mathrm{p}=0.012$ ) without an interaction effect between time and group was found, as shownin Figure 2.

\section{DISCUSSION}

To the best of our knowledge, this is the first study to investigate the influence of Type $\mathrm{D}$ personality on the clinical prognosis of $\mathrm{AF}$ after catheter ablation. Our results suggest that Type $\mathrm{D}$ personality including the NA $\times$ SI interaction was associated with future psychological distress, but had no influence on the onset of recurrence in patients who underwent RFCA for AF. Patients with Type D personality had significantly higher levels of depression and anxiety and a poorer quality of life than patients without Type $\mathrm{D}$ personality. The baseline consisted of the admission period during which the patients were waiting for RFCA for AF. Although this may contribute to negative emotions in the patients with AF, the patients with Type D personality had higher levels of depression and anxiety than the patients without Type $\mathrm{D}$ personality at the time. Moreover, as the physical conditions and psychological distress improved through the 6-month study period, the psychiatric distress of patients with Type D personality remained significantly worse than those of patients without Type D personality.

In the validation study of the Korean DS14 showed that the prevalence of Type D personality in the general population and patients with coronary heart disease was $27.8 \%$ and $26.1 \%$, respectively. ${ }^{24}$ This study showed somewhat higher prevalence, $30.1 \%$ of patients with AF had a Type D personality. This result is similar to that of other Korean studyof $114 \mathrm{pa}-$ tients with chronic AF in which 32\% had Type Dpersonality.22

Type D has been shown to be an independent risk factor for negative health outcomes in various kinds of cardiovascular diseases, including chronic heart failure, ${ }^{7}$ arrhythmias, ${ }^{8}$ heart transplantation, ${ }^{9}$ and coronary heart disease. ${ }^{10}$ However, our results that Type D personality was dissociated from the recurrence of AF suggest that the recurrence rate after RFCA may predominately be influenced by cardiac factors, such as the type of AF. In addition, substitution of the NA and SI scores for the type D classification did not showed any association with $\mathrm{AF}$ recurrence. There were inconsistent findings regarding the effects of personality factors on the outcome of cardiac illnesses. Several studies reported that Type D personality independently contributed to poor prognosis, such as mortality and recurrence of cardiovascular diseases. ${ }^{30,31}$ However, there have also been studies reporting that Type D personality is not related to the clinical prognosis of cardiac diseases ${ }^{32,33}$ including recurrence of AF after electrical cardioversion. ${ }^{12} \mathrm{Un}$ like psychiatric symptoms, such as depression and anxiety, there may be various factors directly influencing cardiac functions, such as the type of AF. In addition, all patients included in this study were treated with catheter-based ablation therapy, which contributed to the homogeneity of our sample. However, according to current guidelines for the AF, ablation therapy is recommended as the secondary treatment for pa- 
tients who are not able to tolerate drugs or who fail the firstline treatment. ${ }^{34,35}$ Thus, the clinical characteristics of our sample may be attributable to the dissociation between personality type and the recurrence of AF.

Patients with AF have been shown to suffer from an increased prevalence of depression and anxiety which associated with poor QoL. Catheter ablation is effective for improving depression, anxiety, and QoL in patients with $\mathrm{AF}^{35}$ Similarly, our results showed that depression, anxiety and poor QoL were improved 6 months after RFCA. However, Type D patients had higher depression and anxiety in addition to poorer QoL compared with non-Type D patients over the study period. As mentioned before, in our study, there were no significant differences in demographic characteristics and cardiologic variables between Type $\mathrm{D}$ and non-Type $\mathrm{D}$ patients. These suggest that Type D personality may play an important role in psychological distress of patients with AF. Depression and anxiety may contribute to negative outcomes including recurrence of $\mathrm{AF}^{12}$ lower QoL, ${ }^{22}$ hospitalization, and cardiovascular mortality ${ }^{36,37}$ although our study did not identify impact of depression and anxiety on the recurrence of AF. Moreover, the association between Type D personality and depression or anxiety may be due to the correlation with the subscales of the DS14 (NA or SI). Accordingly, future study should identify associations between various clinical outcomes of AF and Type D personality controlling potential correlations Type D and psychological distress.

This study has several limitations that should be noted. First, our sample size may not be enough large to ensure there were no associations between Type D personality and the recurrence of AF after RFCA. Second, because we only measured depression, anxiety, and quality of life until 6 months after ablation, we could not confirm whether the differences in depression, anxiety, and quality of life between AF patients with and without Type D personality may have disappeared after a longer period. Third, diagnostic procedures with a structured interview for psychiatric illnesses were not conducted. Although the comorbidity of Type D personality and depressive disorders have been reported to be $7 \%$ among patients with myocardial infarction, ${ }^{38}$ there is a possibility that patients with or without Type D personality could have psychiatric illnesses. Fourth, although personality and related psychiatric distress are important factors for the prognosis of cardiovascular diseases, lifestyles accompanied by personality traits and stress should also be considered. For example, a recent study suggested that Type D personality is associated with lifestyles which may increase the prevalence of coronary artery disease. ${ }^{39}$ Another study suggested that Type D personality was an important factor for the development of cardiomyopathy following emotional triggers. ${ }^{40}$ These findings suggest that the interactions between personality and external factors are important for the clinical prognosis of cardiovascular diseases.

Personality traits are often not considered in the treatment of cardiovascular disease, because many physicians assumed that the risk associated with personality traits cannot be changed. However, emotion, behavior, and cognition related with a personality can be changed by acquired and learned process. Psychiatric interventions can modify the negative emotions of type D patients and effectively prevent the risk of cardiovascular events including AF.

In summary, our results suggest that careful evaluation for Type D personality should be conducted during the acute treatment and management of AF because patients with Type $\mathrm{D}$ have higher levels of depression and anxiety and a poorer quality of life than those without Type D personality. Future studies with a larger sample size and a longer follow-up period are needed to comprehensively evaluate the influence of Type $\mathrm{D}$ personality on the prognosis of AF. If Type $\mathrm{D}$ personality is prevalent in AF patients and is a predictor of poor QoL, it would reinforce the need for services to consider psychosocial interventions when developing care pathways for AF patients with a view to improving outcomes. This would be consistent with current NHS priority of taking a preventative approach in early identification and treatment of AF.

\section{Acknowledgments}

This research is financially supported by a Korea University Grant: no. K1132611 (to Y.H.K). All authors had full access to the data and take responsibility for the integrity of the data and accuracy of the data analysis. For the remaining authors none were declared.

\section{REFERENCES}

1. Denollet J. Type D personality. A potential risk factor refined. J Psychosom Res 2000;49:255-266.

2. Denollet J, Sys SU, Stroobant N, Rombouts H, Gillebert TC, Brutsaert DL. Personality as independent predictor of long-term mortality in patients with coronary heart disease. Lancet 1996;347:417-421.

3. Denollet J. DS14: standard assessment of negative affectivity, social inhibition, and Type D personality. Psychosom Med 2005;67:89-97.

4. Romppel M, Herrmann-Lingen C, Vesper JM, Grande G. Type D personality and persistence of depressive symptoms in a German cohort of cardiac patients. J Affect Disord 2012;136:1183-1187.

5. O’Dell KR, Masters KS, Spielmans GI, Maisto SA. Does type-D personality predict outcomes among patients with cardiovascular disease? A meta-analytic review. J Psychosom Res 2011;71:199-206.

6. Denollet J, Tekle FB, Pedersen SS, van der Voort PH, Alings M, van den Broek KC. Prognostic importance of distressed (Type D) personality and shocks in patients with an implantable cardioverter defibrillator. Int J Cardiol 2013;167:2705-2709.

7. Schiffer AA, Pedersen SS, Widdershoven JW, Hendriks EH, Winter JB, Denollet J. The distressed (type D) personality is independently associated with impaired health status and increased depressive symptoms in chronic heart failure. Eur J Cardiovasc Prev Rehabil 2005;12:341-346.

8. Pedersen SS, van Domburg RT, Theuns DA, Jordaens L, Erdman RA. Type $\mathrm{D}$ personality is associated with increased anxiety and depressive 
symptoms in patients with an implantable cardioverter defibrillator and their partners. Psychosom Med 2004;66:714-719.

9. Denollet J, Holmes RV, Vrints CJ, Conraads VM. Unfavorable outcome of heart transplantation in recipients with type D personality. J Heart Lung Transplant 2007;26:152-158.

10. Denollet J, Pedersen SS, Vrints CJ, Conraads VM. Usefulness of type D personality in predicting five-year cardiac events above and beyond concurrent symptoms of stress in patients with coronary heart disease. Am J Cardiol 2006;97:970-973.

11. van den Broek KC, Nyklicek I, van der Voort PH, Alings M, Meijer A, Denollet J. Risk of ventricular arrhythmia after implantable defibrillator treatment in anxious type D patients. J Am Coll Cardiol 2009;54: 531-537.

12. Lange HW, Herrmann-Lingen C. Depressive symptoms predict recurrence of atrial fibrillation after cardioversion. J Psychosom Res 2007; 63:509-513.

13. Fuster V, Rydén LE, Cannom DS, Crijns HJ, Curtis AB, Ellenbogen KA, et al. ACC/AHA/ESC 2006 Guidelines for the Management of Patients with Atrial Fibrillation: a report of the American College of Cardiology/American Heart Association Task Force on Practice Guidelines and the European Society of Cardiology Committee for Practice Guidelines (Writing Committee to Revise the 2001 Guidelines for the Management of Patients With Atrial Fibrillation): developed in collaboration with the European Heart Rhythm Association and the Heart Rhythm Society. Circulation 2006;114:e257-e354.

14. Benjamin EJ, Wolf PA, D'Agostino RB, Silbershatz H, Kannel WB, Levy D. Impact of atrial fibrillation on the risk of death: the Framingham Heart Study. Circulation 1998;98:946-952.

15. Kerr CR, Humphries KH, Talajic M, Klein GJ, Connolly SJ, Green M, et al. Progression to chronic atrial fibrillation after the initial diagnosis of paroxysmal atrial fibrillation: results from the Canadian Registry of Atrial Fibrillation. Am Heart J 2005;149:489-496.

16. Kreibig SD. Autonomic nervous system activity in emotion: a review. Biol Psychol 2010;84:394-421.

17. Lampert R, Shusterman V, Burg M, McPherson C, Batsford W, Goldberg A, et al. Anger-induced T-wave alternans predicts future ventricular arrhythmias in patients with implantable cardioverter-defibrillators. J Am Coll Cardiol 2009;53:774-778.

18. Carney RM, Freedland KE, Veith RC. Depression, the autonomic nervous system, and coronary heart disease. Psychosom Med 2005;67 (Suppl 1):S29-S33.

19. Howren MB, Lamkin DM, Suls J. Associations of depression with Creactive protein, IL-1, and IL-6: a meta-analysis. Psychosom Med 2009; 71:171-186.

20. Einvik G, Dammen T, Hrubos-Strom H, Namtvedt SK, Randby A, Kristiansen HA, et al. Prevalence of cardiovascular risk factors and concentration of C-reactive protein in Type D personality persons without cardiovascular disease. Eur J Cardiovasc Prev Rehabil 2011;18:504-509.

21. Conraads VM, Denollet J, De Clerck LS, Stevens WJ, Bridts C, Vrints CJ. Type D personality is associated with increased levels of tumour necrosis factor (TNF)-alpha and TNF-alpha receptors in chronic heart failure. Int J Cardiol 2006;113:34-38.

22. Son YJ, Song EK. The impact of type D personality and high-sensitivity C-reactive protein on health-related quality of life in patients with atrial fibrillation. Eur J Cardiovasc Nurs 2012;11:304-312.

23. Carpeggiani C, Emdin M, Bonaguidi F, Landi P, Michelassi C, Trivella $\mathrm{MG}$, et al. Personality traits and heart rate variability predict long-term cardiac mortality after myocardial infarction. Eur Heart J 2005;26:1612-
1617.

24. Lim HE, Lee MS, Ko YH, Park YM, Joe SH, Kim YK, et al. Assessment of the type D personality construct in the Korean population: a validation study of the Korean DS14. J Korean Med Sci 2011;26:116-123.

25. Radloff LS. The CES-D scale: a self-report depression scale for research in the general population. Appl Psychol Meas 1977;1:385-401.

26. Cho MJ, Kim KH. Diagnostic validity of the CES-D(Korean version) in the assessment of DSM-III-R major depression. J Korean Neuropsychiatr Assoc 1993;32:381-399.

27. Spielberger CD, Gorsuch RL, Lushene RE. STAI Manual for the StateTrait Anxiety Inventory. Palo Alto, CA: Consulting Psychologist Press; 1970.

28. Hahn DW, Lee CH, Chon KK. Korean adaptation of Spielberger's STAI (K-STAI). Korean J Health Psychol1996;1:1-14.

29. Min SK, Lee CI, Kim KI, Suh SY, Kim DK. Development of Korean version of WHO quality of life scale abbreviated version (WHOQOLBREF). J Korean Neuropsychiatr Assoc 2000;39:571-579.

30. Denollet J, Pedersen SS, Vrints CJ, Conraads VM. Predictive value of social inhibition and negative affectivity for cardiovascular events and mortality in patients with coronary artery disease: the type d personality construct. Psychosom Med 2013;75:873-881.

31. Schiffer AA, Smith OR, Pedersen SS, Widdershoven JW, Denollet J. Type $\mathrm{D}$ personality and cardiac mortality in patients with chronic heart failure. Int J Cardiol 2010;142:230-235.

32. Grande G, Romppel M, Vesper JM, Schubmann R, Glaesmer H, Herrmann-Lingen C. Type D personality and all-cause mortality in cardiac patients--data from a German cohort study. Psychosom Med 2011;73: 548-556.

33. Volz A, Schmid JP, Zwahlen M, Kohls S, Saner H, Barth J. Predictors of readmission and health related quality of life in patients with chronic heart failure: a comparison of different psychosocial aspects. J Behav Med 2011;34:13-22.

34. Singla S, Karam P, Deshmukh AJ, Mehta J, Paydak H. Review of contemporary antiarrhythmic drug therapy for maintenance of sinus rhythm in atrial fibrillation. J Cardiovasc Pharmacol Ther 2012;17:12-20.

35. Sang CH, Chen K, Pang XF, Dong JZ, Du X, Ma H, et al. Depression, anxiety, and quality of life after catheter ablation in patients with paroxysmal atrial fibrillation. Clin Cardiol 2013;36:40-45.

36. Frasure-Smith N, Lespérance F, Habra M, Talajic M, Khairy P, Dorian P, et al. Elevated depression symptoms predict long-term cardiovascular mortality in patients with atrial fibrillation and heart failure. Circulation 2009;120:134-140.

37. Frasure-Smith N, Lespérance F, Talajic M, Khairy P, Dorian P, O’Meara E, et al. Anxiety sensitivity moderates prognostic importance of rhythmcontrol versus rate-control strategies in patients with atrial fibrillation and congestive heart failure: insights from the Atrial Fibrillation and Congestive Heart Failure Trial. Circ Heart Fail 2012;5:322-330.

38. Denollet J, de Jonge P, Kuyper A, Schene AH, van Melle JP, Ormel J, et al. Depression and Type D personality represent different forms of distress in the Myocardial INfarction and Depression - Intervention Trial (MINDIT). Psychol Med 2009;39:749-756.

39. Svansdottir E, Denollet J, Thorsson B, Gudnason T, Halldorsdottir S, Gudnason V, et al. Association of type D personality with unhealthy lifestyle, and estimated risk of coronary events in the general Icelandic population. Eur J Prev Cardiol 2013;20:322-330.

40. Compare A, Bigi R, Orrego PS, Proietti R, Grossi E Steptoe A. Type D personality is associated with the development of stress cardiomyopathy following emotional triggers. Ann Behav Med 2013;45:299-307. 